\title{
El fratricidio: antecedentes épicos y derivaciones trágicas de un tópico resemantizado en la figura del exilio edípico en Fenicias de Eurípides
}

\section{Fratricide: Epic Background and Tragic Directions of a Topic Re-emphasized in the Figure of the Oedipus' Exile in Euripides' Phoenissae}

\author{
Bruno D. AlfonZO \\ https://orcid.org/0000-0001-6200-0821 \\ Universidad Nacional de San Martín, Argentina \\ brunodalfonzo@gmail.com
}

\begin{abstract}
ResumEN: El siguiente trabajo aborda el fratricidio entendido como tópico de la cultura occidental, introduciendo sus significativas proporciones a partir de los distintos abordajes que en época moderna se han llevado adelante respecto de su función en la literatura. El estudio se aboca a la delimitación del tópico en el ámbito de la literatura griega en relación con el devenir de la progenie edípica. Así, parte de la épica griega arcaica para llegar a la tragedia, contrastando los elementos míticos que una y otra presentan como sostén de su relato. La tesis central, que manifiesta que el fratricidio de Eteocles y Polinices constituye un castigo dirigido a la figura de Edipo mediante su exilio, encuentra su consumación en Fenicias de Eurípides, cuya originalidad se hace manifiesta a partir de un estudio comparado de las fuentes.
\end{abstract}

Palabras Clave: Fratricidio, Edipo, tragedia griega, exilio, Eurípides

ABSTRACT: The following work deals with fratricide as a topic in Western culture and its role in literature from the different approaches in modern times. The paper focuses on the delimitation of the topic within Greek literature through the evolution of Oedipus' offspring', from Archaic Greek epic to tragedy. Thus, it starts contrasting the mythical elements that both, epic and tragedy, display as a support of each story. My hypothesis is fratricide of Eteocles and Polynices becomes a punishment to Oedipus through his exile, and that its consummation is in Euripides' Phoenissae, which I conclude through a comparative study of the sources. 
Keywords: Fratricide, Oedipus, Greek Tragedy, Exile, Euripides

ReCiBIDO: 19/05/2020 • ACEPTADO: 23/06/2020 • Versión finAL: 01/11/2020

\section{INTRODUCCIÓN}

El mito de Edipo se ha constituido como uno de los relatos antiguos más abordado a lo largo de la historia. Sin dudas, debemos a Sigmund Freud el haber inmortalizado su legado a través de las interpretaciones que realizó con base en el Edipo Rey de Sófocles. ${ }^{1}$ No obstante, más allá de esta deuda con el padre del psicoanálisis, cualquiera que haya leído la pieza reconoce el valor intrínseco que representa. En efecto, si bien Edipo se ha vuelto una figura popular debido a la teoría levantada por el doctor Freud, hace ya tiempo ha sido cometido el parricidio que nos ha permitido dejar a un lado a este agudísimo espíritu europeo y estudiar la emblemática figura del rey tebano desde otras perspectivas. ${ }^{2}$

Nuestro trabajo, si bien no directamente, se encuentra estrechamente relacionado a la problemática nacida de la tragedia edípica. En efecto, la pieza que hemos seleccionado relata lo acontecido a dos de los hijos de Edipo: Eteocles y Polinices. Nuestro objetivo será abordar el doble fratricidio por el que ambos se ven signados a partir de los testimonios de la épica arcaica y la tragedia clásica para, en esta última, llegar a detenernos en la versión euripídea. Nuestro estudio relevará los datos que estas fuentes transmiten, con el fin de extraer algunas conclusiones que puedan dar cuenta de ciertas peculiaridades que reviertan interpretaciones precedentes. La comparación, preciado instrumento, ${ }^{3}$ constituye uno de los elementos de nuestro método: pues se trata de comparar nuestras intuiciones con el texto y, a su vez, elementos de este con versiones anteriores para, de allí, extraer conclusiones que permitan obtener buenos resultados.

Luego de la lectura de Fenicias, algo sugería a este autor que el fratricidio griego debía significar algo más que el cumplimiento de una maldición del padre, y esto responde a dos motivos: en primer lugar, las diferencias

${ }^{1}$ En algunos manuales es usual encontrar la aseveración de que la primera mención que Freud hace del Ödipuskomplex aparece en sus Beiträge zur Psychologie des Liebeslebens, de 1910. No obstante, su gestación se halla ya en el capítulo V de Die Traumdeutung, de 1899. Consignamos al lector la versión en español que manejamos: Freud 2017, pp. 506 y ss.

${ }^{2}$ Recomiendo especialmente la de Goux 1990. Existe una brillante traducción al español a cargo de Pinkler 1999.

${ }^{3}$ Comparto el parecer de Stefan Zweig: "Siempre me ha parecido la comparación un elemento creador de gran eficacia, y hasta me gusta como método, ya que puede ser usado sin la necesidad de forzarse; así como las fórmulas empobrecen, la comparación enriquece, pues realza los valores...". Zweig 1999, p. 9. 
capitales que presenta el relato euripídeo respecto de otros. Y, a su vez, las divergencias que manifiesta respecto de una fuente más antigua que debió servir de inspiración al poeta: el Ciclo Tebano. Más adelante se comprederá este primer nivel de la investigación, de suyo cardinal.

En segundo lugar, una intuición apuntaba que este argumento -el argumento fratricida - era históricamente significativo. En efecto, cualquiera puede comprobar su presencia en diversas fuentes de las literaturas sagrada y profana. Sólo basta conocer el Génesis y el mito de la fundación de Roma para alcanzar una visión clara de ello. Quisiera, en adelante, profundizar este rasgo a modo de introducción.

Otto Rank, psicoanalista de envergadura y colega de Sigmund Freud, señaló un subgénero literario bajo el que bien podrían subordinarse los fratricidios de Eteocles y Polinices junto con el de Caín contra Abel ${ }^{4}$ y el de Rómulo contra Remo. ${ }^{5}$ Se trata de los Brüder-Mythen, a saber, aquellos mitos en los que se presenta una relación entre hermanos que, por lo general, es hostil. En este sentido, Rank nos dice que "the complications of the hero myth with other myth cycles include, besides the myth of the hostile brothers, [...] also the actual incest myth". ${ }^{6}$ Lo que significa que los mitos de hermanos hostiles constituyen una vertiente particular del mito del héroe, al igual que el mito del incesto. Volvemos aquí a Edipo, pues en él aparece no sólo el incesto, sino, a su vez, el fratricidio producto de la maldición que arroja sobre sus hijos. Si bien Rank refiere este subgénero del mito del héroe $^{7}$ como una parte relevante de la literatura mítica, no aporta mucho más. Sus observaciones tienen como objetivo extraer consideraciones afines al campo del psicoanálisis, como bien nos lo indica el subtítulo de su obra: Versuch einer psychologischen Mythendeutung.

En el mismo sentido, pero ampliando su alcance, Freud nos dice que "es de suponer que al parricidio le sucedió una prolongada época en la cual los hermanos se disputaron la sucesión paterna, que cada uno pretendía retener para sî́". ${ }^{8}$ Herbert Marcuse, en consecuencia, nos informa que "el mando del padre original es seguido, después de la primera rebelión, por el mando de los hijos, y el clan de hermanos se desarrolla como dominación social y política institucionalizada". ${ }^{9}$ Estas consideraciones parten de la idea del sentimiento de culpa como elemento constitutivo en la conciencia de los hermanos, a

\footnotetext{
${ }^{4}$ Gen. 4. Recomiendo la lectura de Frazer 1981, p. 50 y Lipscomb 1990, pp. 145 y ss.

${ }^{5}$ Sobre Rómulo y Remo las fuentes son diversas, y las versiones que cada una de ellas manifiesta, también. Las principales son: Plu., Rom.; Liv., I; Eutr., I; Strab., V. Para una introducción al relato véase Grimal 2005, pp. 11 y ss.

${ }^{6}$ Rank 1914,p. 88.

${ }^{7}$ Respecto del mito del héroe, véase Bauzá 2007.

${ }^{8}$ Freud 2017, p. 3290.

${ }^{9}$ Marcuse 1983, p. 30.
} 
cuyo padre han asesinado. Aquí, la relación entre los hermanos se encuentra siempre intervenida por los efectos de un parricidio originario inmediato.

En otro orden de ideas, contamos con los estudios antropológicos. En efecto, el fratricidio ha sido estudiado más allá de la literatura y el psicoanálisis como una dinámica propia de las sociedades primitivas. Lucien LévyBruhl se pregunta: "Les sociétés primitives connaissent-elles une prohibition de l'autophagie, ou du fratricide? Elles n'ont ni plus ni moins de raison de prohiber l'inceste". ${ }^{10}$ Como vemos, el fratricidio vuelve a relacionarse con el incesto. En este caso, el autor nos muestra irónicamente cómo la no prohibición de éste encuentra su fundamento en el hecho de que el fratricidio y la autofagia sean realidades corrientes. En efecto, no hay prohibición que pese sobre estas últimas, por lo que nada exige que sí la haya sobre el incesto: puede apreciarse la naturalidad con la que se acepta aquí al fratricidio. Al respecto, en Les structures élémentaires de la parenté, pueden hallarse algunas consideraciones en el mismo sentido por parte de Claude Lévi-Strauss. ${ }^{11}$

¿Por qué es importante reconocer la permanencia histórica del fratricidio en tanto tópico? ¿Qué nos aporta? Lo cierto es que en este recorrido sumario vemos cómo el fratricidio es una experiencia que aparece en diversas prácticas humanas, ya sean estas creaciones mítico-literarias o bien representen un devenir histórico. En la literatura, si uno se dedica a estudiarla, se pueden encontrar múltiples escenas en que un fratricidio o una relación hostil entre hermanos son nucleares. Un ejemplo cercano lo constituye la emblemática pieza Hamlet de Shakespeare, en la que un rey es asesinado por su propio hermano. ${ }^{12}$ Aquí, en el orden de lo literario, contemplamos también el relato veterotestamentario y las fuentes que nos transmiten el fratricidio de Rómulo contra Remo. A su vez, los diversos relatos míticos de otras tradiciones, relevados en gran parte tanto por la crítica literaria, como por el psicoanálisis y la antropología. En cuanto a esta última, debe evitarse asociar de forma exclusiva la práctica del fratricidio a grupos sociales por lo general llamados primitives. En primer lugar, no en todos ellos el fratricidio es una experiencia frecuente. Por otro lado, también existen - esto es lo que dramatiza Shakespeare - fratricidios en las esferas de la aristocracia moderna. ${ }^{13}$

\footnotetext{
${ }^{10}$ Lévy-Bruhl 1931, p. 247.

${ }^{11}$ Recomiendo el trabajo de Hozven 1979, pp. 51-89, fundamentalmente el cuadro de la p. 72 y su explicación.

12 Véase Jaspers 1947, p. 62; también, el estudio que le sirviera de inspiración: Werder 1893. Es curioso que el propio Freud, en un artículo que publicara anónimamente en 1914 en la revista Imago, señale que el argumento de Hamlet es esencialmente edípico, opinión discutida por Harold Bloom 1995, p. 384.

${ }^{13}$ Un antecedente peculiar lo constituye la denominada Sächsischer Bruderkrieg, la guerra fratricida sajona, que se libró en el año 1446 enfrentando a los hermanos Federico II y Guillermo III, en disputa por los territorios que pertenecían a la Casa de Wettin. Si bien la guerra
} 
¿Qué hallamos en la filosofía? De entre sus diversos aportes, encontramos lo manifestado por E. Albizu en su Teoría del contratiempo implosivo, obra en la que expresa, de acuerdo con su lectura de G. W. F. Hegel, la identificación del fratricidio con el origen de la autoconciencia: "En el capítulo IV de la Fenomenología del Espíritu, Hegel confirma la experiencia del Génesis: el fratricidio es el origen de la autoconciencia. [...] Las luchas de clases han de ser vistas como formas de fratricidio que reproducen en katábasis el originario arquetipo temporal". ${ }^{14}$

Creemos que la conclusión a la que arriba Albizu procede por inspiración de no otro espíritu elevado que el de Karl Marx. En Das Kapital se traduce la figura del fratricidio en la lucha entre los hombres, particularmente entre clases sociales, pero ante todo entre los hombres per se. En este sentido, el fratricidio deja de ser entendido a partir de una consanguinidad biológica; se comprende una idea de fraternidad asociada a los lazos que unen a los hombres bajo una misma especie. Sólo así es como llegamos a entender que en Hegel el fratricidio sea el origen de la autoconciencia, sobre todo cuando el autor que nos lleva a comprenderlo de este modo menciona el capítulo IV de la Fenomenología; nada menos que el emblemático apartado en que Hegel expone la Selbständigkeit und Unselbständigkeit des Selbstbewußtseins; Herrschaft und Knechtschaft: la dialéctica del amo y el esclavo. Esta lucha entre hombres, entre hermanos, vendría a ser una repetición de la maldición que pesa sobre Caín. En este sentido, el enfoque no difiere demasiado del de Freud, salvo que aquí entra en juego la lucha de clases - aspecto desconocido por el psicoanálisis - y se señala a Caín como el "primer dominador. La estructura elemental de la conciencia de clase se yergue así: a los otros, a los de otras clases, los odio porque son mis enemigos, porque me han despojado o quieren despojarme del poder económico propio de mi clase". ${ }^{15}$ Aquí es Caín quien habla. Si tomamos en consideración las condiciones previas por las que Caín asesina a Abel, tal vez esta interpretación no sea tan descabellada. En efecto, podemos improvisar la siguiente explicación: Caín representa la clase agrícola, de cuya siembra cosecha su ofrenda. Abel constituye la clase ganadera, por defecto propietaria, en una superior posición social, y por lo tanto portadora de una dote más valiosa que consiente los intereses de Yahvé. Postular qué rol ocuparía aquí este Dios ganadero está por fuera de nuestras capacidades.

Con todo, es en este espíritu que Marx cita ${ }^{16}$ a Horacio, transcribiendo unos versos naturalmente no vinculados al mito de Caín y Abel, sino ahora al de Rómulo y Remo:

culminó con un acuerdo pacífico y ninguno de los dos hermanos terminó muerto a causa del enfrentamiento, la lucha entre ambos duró cinco años, hasta enero de 1451.

${ }^{14}$ Albizu 2006, p. 298.

15 Ibid., p. 299.

${ }^{16}$ Marx 2002, p. 2064. 
Sic est: acerba fata Romanos agunt, scelusque fraterne necis. ${ }^{17}$

Marx no traduce estas líneas. No obstante, antes de ofrecer nuestra traducción, creemos conveniente adicionar los versos subsiguientes. Estos no son referidos por Marx, pero creemos que aclararán lo que Horacio quiere decirnos y lo que, a través de él, el filósofo alemán pretende comunicar:

\section{Ut immerentis fluxit in terram Remi sacer nepotibus cruor. ${ }^{18}$}

Una traducción conveniente sería la siguiente:

Un amargo destino conduce a los romanos:

el crimen del asesinato de un hermano;

la sangre del inocente Remo manchó la tierra que expiarán sus descendientes. ${ }^{19}$

Horacio acusa a los romanos ante la situación social en que se encuentra inmersa Roma. Aquí el mito de Rómulo y Remo es menos una creencia del poeta que un recurso estrictamente poético. Horacio hace una referencia directa a la guerra civil ${ }^{20}$ en la que se encuentra inmersa Roma en el momento en que escribe estos versos. De ahí que Marx cite los dos primeros, donde se menciona el fratricidio. Marx denuncia este asesinato pero amplía el concepto que probablemente asumía Horacio. El poeta, en efecto, se refiere a Rómulo y Remo, por lo que pareciera restringir el concepto de hermano a una relación al interior de un pueblo, que para él es el pueblo romano. Marx, en cambio, se refiere a un concepto fratricida en el cual todos los seres humanos son hermanos. ${ }^{21}$ En el filósofo, se trata de un concepto universal,

${ }^{17}$ Hor., Epod., VII, 17-18.

${ }^{18}$ Hor., Epod., vv. 19-20.

${ }^{19}$ La traducción es nuestra. Para un tratamiento riguroso del poema, véase Carruba 2014, pp. 29-34.

${ }^{20}$ Horacio es sólo un ejemplo de cómo la guerra civil conjuraba para los poetas romanos una guerra fratricida. En Ovidio, Lucano y Séneca podemos encontrar, incluso, referencias directas al fratricidio tebano, inspiradas por la situación social de la Roma convulsa de esos tiempos. Para este tema, véase Criado, "The Theban Fratricidal Wars. The Mythic-Historical Aproach of Ovid, Seneca and Lucan”, en Díaz de Cerio Díez 2015. Para abordar en particular la recepción de Lucano en su Bellum civile: Ambuhl 2015.

${ }^{21}$ Es en este sentido que podemos comprender el hecho de que a diversos enfrentamientos civiles y militares contemporáneos se los denomine, en ocasiones, "guerras fratricidas". Desde la década de 1980, en efecto, ese ha sido el nombre con que se ha bautizado al enfrentamiento permanente entre la República Islámica de Irán y la República de Irak. 
que, aun así, extrae de Horacio y, en esencia, repite la interrogante de Hölderlin: ¿No son hermanos tuyos todos los hombres? ${ }^{22}$

Lo que intentamos hacer aquí es considerar con cierta heterodoxia disciplinar la dimensión histórica que rodea al argumento fratricida y, con ello, señalar la riqueza temática que lo circunda. Lo que en todo caso puede concluirse de este recorrido introductorio es lo siguiente: el fratricidio griego es sui generis, pues presenta una peculiaridad que ningún otro fratricidio ha llegado a experimentar: se trata de un doble crimen, un fratricidio en que ninguno de los dos hermanos envueltos prevalece por sobre el otro. Aquí no hay lugar para autoconciencias, pues los arquetipos de Caín y Abel y de Rómulo y Remo presentan una experiencia en que la muerte avanza sobre uno solo de los contendientes.

\section{El Ciclo tebano}

\section{1. La Edipodia}

Sobre la Edipodia conservamos un solo testimonio que atribuye la pieza a un posible autor; según la Tabula Borgiana, se trata de Cinetón, poeta lacedemonio del que no se poseen datos precisos. La misma fuente nos revela que la Edipodia constaba de seis mil versos, de los cuales nos han quedado sólo referencias directas e indirectas de otros autores. A continuación, referiremos las primeras para ofrecer al lector el material con que contamos:

i. No creo que llegara a tener hijos de ella (de Yocasta), a juzgar por el testimonio de Homero, que dice en la Odisea: «Vi a la madre de Edipo, a la hermosa Epicasta, que cometió una gran falta por las ignorancias de su mente, al casarse con su propio hijo. Él, tras haber dado muerte y despojado a su padre, la desposó. Pero inmediatamente los dioses lo hicieron notorio entre los hombres». ${ }^{23}$ ¿Cómo, pues, lo habrían hecho notorio inmediatamente si efectivamente hubiera tenido Edipo cuatro hijos de Epicasta? Por tanto, fue de Eurigania, la hija de Hiperfante, de quien nacieron. Lo manifiesta también el autor del poema épico que llaman la Edipodia. $^{24}$

ii. Los que escribieron la Edipodia — ningún otro habla de este modo acerca de la Esfinge- dicen: Pero además [la Esfinge devoró] al más hermoso y deseable de todos, al hijo amado del irreprochable Creonte, al divino Hemón. ${ }^{25}$

\footnotetext{
${ }^{22}$ Citado por Zweig 1999, p. 50. El autor no revela la fuente.

${ }^{23} \mathrm{El}$ testimonio refiere a la escena de la katábasis de Odiseo, en la que el héroe se encuentra con Yocasta (Epicasta para Homero) en las puertas del Hades: Od., XI, 271-280.

${ }^{24}$ Paus., IX, 5, 10. Salvo donde se indique lo contrario, para los fragmentos y testimonios del Ciclo tebano seguimos la traducción de Bernabé Pajares 1999.

${ }^{25}$ Escolio Cód. Mon. 560, a E., Ph., 1760.
} 
De ambos, es el primer testimonio el que nos interesa. Pausanias nos dice que, de acuerdo con la Edipodia, Eteocles, Polinices, Ismene y Antígona no serían el producto de la unión entre Edipo y Yocasta, sino que Edipo habría tenido una segunda esposa, Eurigania, quien concibiera a los cuatro hermanos. Veremos más adelante qué implicaciones tiene este antecedente en nuestro estudio.

Ahora bien, contamos con otras referencias sobre la quaestio edípica, que en este caso son indirectas, pues no invocan a la Edipodia. Una de ellas es la de Pisandro, aparecida, al igual que la segunda referencia directa que hemos citado, en un escolio de Fenicias. Pisandro probablemente fuera un mitógrafo helenístico que tuvo contacto con la Edipodia, tal vez no de forma directa; es verosímil que haya tratado con algún resumen de ella. ${ }^{26} \mathrm{El}$ testimonio es extenso, por lo que citaremos solamente lo que nos concierne:

Luego [Edipo] se casó con su madre [...] Dicen que después de la muerte de Yocasta y su propia ceguera se casó con la doncella Eurígana, de la que le nacieron los cuatro hijos. Hasta aquí, lo que dice Pisandro. ${ }^{27}$

En este fragmento se refuerza lo que sabíamos a partir del testimonio de Pausanias. En efecto, Edipo habría tenido un segundo matrimonio con una tal Eurigania o Eurígana, distinta a la Yocasta o Epicasta que encontramos en las versiones trágicas y en la versión épica de Homero, respectivamente. De la Edipodia, conservaremos este dato. Tenemos el testimonio directo de Pausanias y la referencia indirecta de Pisandro aparecida en un escolio de Fenicias. Esto nos hace pensar que existía la versión de que Edipo había consumado otro matrimonio luego de que Yocasta se suicidara. Incluso, podemos llegar a considerar este hecho si nos atenemos a lo que dice Homero en la Odisea:

Él [Edipo], sufriendo dolores, siguió rigiendo en Tebas sobre los cadmeos, por funestos designios de los dioses. Y ella [Epicasta] se fue a la morada del fuerte Hades, de puertas sólidamente cerradas, atándose un lazo suspendido del alto techo, rendida por su propio sufrimiento. ${ }^{28}$

Homero nos dice que Epicasta - otro nombre, dijimos, con que el poeta se refiere a Yocasta - se suicidó luego de revelarse que Edipo era su hijo. Presa del sufrimiento, se colgó en el palacio. Pero lo más importante aquí es lo que se nos dice sobre Edipo: "siguió rigiendo en Tebas sobre los cadmeos". Según esto, Edipo no habría sido expatriado de la ciudad, y no parece que hubiera podido seguir gobernando si ante la revelación de sus trá-

\footnotetext{
${ }^{26}$ Según lo que sugiere Bernabé Pajares 1999, p. 44.

${ }^{27}$ Pisand., fr. 10, Jacoby.

${ }^{28}$ Hom., Od., XI, 275-280. La traducción es nuestra.
} 
gicos actos se hubiera arrancado los ojos. Más allá de que el poeta nos diga

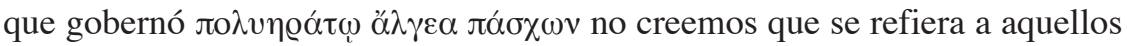
padecimientos inherentes a una violenta ceguera, aunque Pisandro sí afirme que la segunda unión de Edipo haya acontecido después de esta autoinflicción. Sea como sea, Homero sustenta la idea de que Edipo continuó siendo rey de Tebas por algún tiempo en el que, sospechamos, probablemente haya conocido a Eurigania, con la cual tuviera luego a sus cuatro hijos. Esta hipótesis se refuerza con lo que Homero agrega en la Ilíada a propósito de Euríalo, hijo de Mecisteo:

\section{[...] que en otro tiempo llegó al entierro del abatido Edipo. ${ }^{29}$}

Euríalo estuvo presente en los funerales de Edipo, que tuvieron lugar en Tebas. Esta versión, que nos da la impresión de que Edipo jamás fue expatriado de la ciudad, además de contradecir la muerte áurea que Sófocles nos ofrece en su Edipo en Colono, ${ }^{30}$ nos lleva a reforzar la idea de que Edipo permaneció en la ciudad el tiempo suficiente como para unirse a una segunda esposa y dejar descendencia.

De lo dicho hasta aquí sobre la Edipodia debemos quedarnos con dos elementos, que serán útiles a la hora de indagar la tragedia y, en particular, la obra de Eurípides que reconstruye el enfrentamiento fratricida:

a. De acuerdo con lo que nos dice Pisandro, en consonancia con lo que nos revela la tragedia sofoclea, ${ }^{31}$ Yocasta (o Epicasta) se suicida tras conocer la verdad subyacente a los hechos. De este modo, la madre y esposa de Edipo no sería testigo de lo que sucedería después con Eteocles y Polinices.

b. Ahora bien, quizá Yocasta ni siquiera conoció a estos dos muchachos, pues según lo que nos cuenta Pausanias y lo que pudimos considerar a partir del testimonio homérico, tanto Eteocles y Polinices serían hijos - junto con Antígona e Ismene- de Eurigania, segunda esposa de Edipo, por lo que los hermanos fratricidas nada tendrían que ver con Yocasta, quien se habría suicidado antes de la unión de Edipo con esta otra mujer. En la versión trágica tradicional, Yocasta sí es progenitora de la descendencia edípica, como puede intuirse a partir de las siguientes palabras del adivino Tiresias:

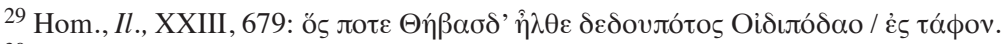

${ }^{30}$ S., $O C ., 1587-1667$.

${ }^{31}$ De hecho, podemos suponer que la versión de Sófocles haya tenido en cuenta el testimonio pisandrino, siendo que el nombre de este último figura tercero en el Canon alejandrino, luego de Homero y de Hesíodo, lo cual revela una relativa importancia del poeta.
} 
[...] será manifiesto que él mismo [Edipo] es, a la vez, hermano y padre de sus propios hijos. ${ }^{32}$

En suma, debemos preservar la idea de que Yocasta se suicidó luego de enterarse que Edipo era su hijo y, por otro lado, el hecho de que la madre de Eteocles y Polinices no fue ella, sino una tal Eurigania.

\section{2. La Tebaida}

En lo que respecta a la atribución de esta obra, la Tabula Borgiana no nos da ningún dato válido, pues justo el pasaje en que figuraba el nombre del autor se ha perdido:

[...] la Tebaida, de seis mil seiscientos versos, dicen que es de (...) de Mileto. ${ }^{33}$

En todo caso, lo que sabemos es que el autor era oriundo de Mileto y que la pieza constaba, al igual que la Edipodia, de seis mil versos. Esta información contrasta con lo que refiere Pausanias:

Calino, que hace mención de ellos [esto es, de los versos de la Tebaida] dijo que fue Homero el que la compuso. ${ }^{34}$

De este modo, de acuerdo con lo que nos dice Pausanias, Calino, lírico de Éfeso del siglo vIII, atribuye la composición del poema a Homero, como era frecuente.

De la Tebaida poseemos una cantidad de referencias directas más considerable que la que poseemos sobre la Edipodia. No obstante, muchas de ellas no son afines a los objetivos de este estudio, por lo que nos limitaremos a relevar solamente dos, que nos aportan datos importantes respecto de los antecedentes del fratricidio tebano:

i. Edipo, por causa de unas copas, maldijo a sus hijos, según dice el autor del poema cíclico la Tebaida, porque le ofrecieron una copa que les había prohibido, diciendo lo siguiente: [...] Pero cuando éste [Edipo] reconoció, puestos ante él, los preciosos presentes de honor de su propio padre, una gran aflicción se apoderó de su ánimo, y al punto en presencia de sus hijos los maldijo con terribles imprecaciones (y no se le ocultó a la Erinis de los dioses): ;Que no se distribuyeran el patrimonio en amigable hermandad, sino que por siempre entre ambos hubiera guerras y combates! ${ }^{35}$

${ }^{32}$ S., OT., 457-458.

${ }^{33}$ Seguimos la edición de la Tabula: CIG Itat. et. Sic., 1292, II, 9, reproducida por Kinkel, Epicorum..., p. 4, contenida y traducida por Bernabé Pajares 1999.

${ }^{34}$ Paus., IX, 9, 5 = Callin., fr. 6.

${ }^{35}$ Ath., 465 e. 
ii. [...] Los servidores de Eteocles y Polinices, que tenían por costumbre enviarle a su padre, Edipo, como parte de cada víctima, un brazuelo, olvidados de ello una vez $[\ldots]$ le enviaron un anca. Y él, con espíritu mezquino y de una forma pese a todo completamente innoble, lanzó imprecaciones contra ellos, por considerar que lo menospreciaban. Eso es lo que el autor del poema cíclico la Tebaida refiere del siguiente modo: Cuando reparó en el anca, la tiró por tierra y dijo estas palabras: - ¡Ay de mí! ¡Mis hijos, por injuriarme, me enviaron esto! Imprecó a Zeus soberano y a los demás inmortales, para que ambos bajaran a lo profundo del Hades por obra de las manos del otro. ${ }^{36}$

Veamos el primer fragmento. En él se manifiestan las causas que motivaron la primera de las dos maldiciones que Edipo arroja contra sus hijos Eteocles y Polinices. Observamos a Edipo, aparentemente en el palacio junto a los muchachos, dispuesto a compartir con ellos una copa de vino. No hay rastros de Yocasta ni de Eurigania, tampoco de sus hijas Ismene y Antígona. Podemos figurarnos a Edipo reposado en sus dignos aposentos compartiendo un momento con sus hijos varones. Luego se nos dice que Polinices coloca frente a su padre una mesa de plata que perteneciera a Cadmo, sobre la que apoya una copa de oro en la que el líquido de Dioniso es vertido en ofrecimiento a Edipo. Éste se da cuenta de que dicha copa era una antigua pertenencia de su padre, Layo, lo cual le recuerda el trágico asesinato que cometiera contra su persona. Evidentemente Edipo recibe este gesto como una ofensa deliberada por parte de sus hijos, y los maldice augurándoles un futuro calamitoso en que la enemistad y la lucha rubriquen la relación entre ambos.

¿Qué nos dice este relato? En primer lugar, podemos asegurar que se encuentra en consonancia con lo que Homero, Pausanias y Pisandro nos refieren respecto de lo acontecido con Edipo luego de la revelación de su hado. En efecto, el vate griego nos decía que Edipo siguió gobernando en Tebas y que fue allí donde se le dio sepultura tras su muerte. Pausanias y Pisandro nos informaban que Edipo, tras el suicidio de Yocasta, se casó con Eurigania, madre de sus cuatro hijos, lo cual refuerza la idea de que habría permanecido en el reino. Evidentemente, este fragmento de la Tebaida apoya esa idea: Edipo permaneció en Tebas. Además, encontramos en este testimonio una constatación de lo que suponíamos antes en contra de Pisandro y a favor de Homero: Edipo no invalidó su vista. En ese caso, no habría sido capaz de identificar la copa de Layo. Por otra parte, al no haber rastros de Yocasta, podemos suponer que ésta ya se habría suicidado, y que en el momento en que ocurre la escena aquí tratada, Edipo se encontraba unido a Eurigania, madre de sus hijos.

En resumen, estamos frente a un Edipo posrevelación, aparentemente relajado, vidente, sin demasiadas contrariedades. No obstante, pareciera que su pasado parricida todavía lo persigue, pues al instante que visualiza la

\footnotetext{
${ }^{36}$ Escolio L a S., OT., 1375.
} 
copa de su padre, enloquece y maldice a sus hijos. Este hecho es el que vuelve irrefutable - en cuanto a lo que nos trasmiten los fragmentos y testimonios del Ciclo tebano - la prueba de que Edipo permaneció en la ciudad de Cadmo luego de las noticias trágicas, de la misma manera que robustece la tesis de que no sufrió autoinflicción alguna. Del mismo modo que si hubiera estado ciego no podría haber visto la copa, no se habría consternado al verla si no hubiese tenido conocimiento alguno de su asesinato.

Vayamos ahora al segundo fragmento, donde se consuma la segunda maldición de Edipo. Se trata de una escena algo absurda, pues según se nos dice, era costumbre que Eteocles y Polinices, por medio de sus servidores, ofrecieran a Edipo un brazuelo de cada una de sus víctimas. ${ }^{37}$ Aparentemente, en una ocasión los hermanos olvidaron este hábito y en vez de ofrecer a su padre un brazuelo, ofrecieron un anca. ${ }^{38}$ Edipo se encoleriza por lo que entiende es una ofensa contra su dignidad y maldice a sus hijos augurándoles una occisión fratricida en que se den muerte uno al otro. La reacción de Edipo, como lo señala el propio autor de este testimonio, es bastante exagerada. A menos que tuviera la certeza de que sus hijos cometieron esta acción con el objetivo de humillarlo, no se entiende demasiado su intransigencia. A decir verdad, pareciera que Edipo, o bien presentaba un temperamento muy susceptible e iracundo - aspecto que contradice en gran medida lo que nos transmite Sófocles, exceptuando aquella escena en que Edipo comete hýbris contra Tiresias,$-{ }^{39} \mathrm{o}$ bien permanecía en él una animadversión particular contra Eteocles y Polinices, por quienes sentía poca confianza y hasta reconocía como deshonestos. Como sea, lo que debe quedarnos de este fragmento es la maldición que oficiará de consigna en el desenlace que aquí estudiamos.

\section{LOS SIETE CONTRA TEBAS}

Antes de abordar la experiencia trágica, debemos justificar la ausencia de un tratamiento exhaustivo de la versión sofoclea. Lo cierto es que, si bien Sófocles dedicó parte de su obra a la contienda entre los hermanos, ninguna de sus piezas se aboca especialmente a ella. Por ello, nos hemos limitado a escudriñar las piezas de Esquilo y de Eurípides que sí lo hacen.

\footnotetext{
${ }^{37}$ Aquí debemos entender que el escoliasta se refiere a víctimas animales, destinadas al consumo de los ciudadanos, aunque parece raro que Eteocles y Polinices tuvieran por tarea carnear el ganado que sería luego consumido por el resto. No queda muy claro.

${ }^{38} \mathrm{El}$ escoliasta parece sospechar que este "olvido" haya sido deliberado.

${ }^{39}$ S., OT., 429-447. Esta escena es vista como el segundo momento del destino edípico - clásico en la tragedia - iniciado por la ate "ceguera" y culminado en némesis o afáneia. Por

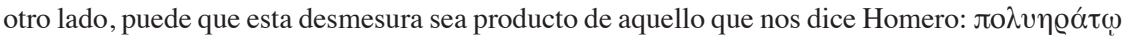

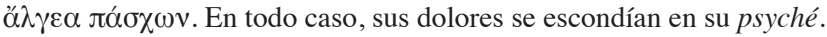


Vayamos directamente a los elementos del mito que podemos extraer de Los siete contra Tebas para distinguir qué ha escogido Esquilo como sostén de su composición. Para ello, además de tener en cuenta los personajes que participan en su obra, debemos tener presentes algunas escenas de marcada relevancia.

Hay tres momentos que nos parecen importantes, que tienen como protagonista al Coro, a partir de los cuales podemos conjeturar la versión del mito que Esquilo manipula:

CORO:

i. Vencido por su propia irreflexión, llegó a engendrar su propia muerte, al parricida Edipo, que sembró el puro campo materno donde él se crió, con lo que osó hacer brotar una raíz llena de sangre. ¡Locura destructora de almas unió a los esposos! ${ }^{40}$

ii. Pero, luego que el desdichado se hizo consciente de su triste boda [...] se saltó los ojos. ${ }^{41}$

iii. Luego, resentido con sus hijos por aquella comida de antaño - ¡ay, ay! - profirió con amarga lengua las maldiciones. ${ }^{42}$

Proyectemos algo de luz en cada uno de los fragmentos:

i. El primero invoca directamente a Layo, no a su hijo. Las jóvenes refieren aquella trasgresión que cometió el primero al haber engendrado a Edipo. Pero lo más importante es lo que sigue: "que sembró el puro campo materno donde él se crió". Esta afirmación - esta vez sobre Edipo - es la prueba de que Esquilo mantiene la versión según la cual Eteocles, Polinices, Ismene y Antígona son hijos de Yocasta y no de otra mujer. Habíamos visto, a partir de los testimonios de Pisandro y Pausanias, que la descendencia edípica podía atribuirse a Eurigania, presunta segunda esposa con la que Edipo habría yacido luego de la muerte de Yocasta, tras cuya unión nacieron los hermanos. Esquilo, entonces, sostiene la versión que para nosotros es tradicional.

ii. El segundo fragmento nos revela lo que habíamos puesto en discusión a partir de lo que Homero nos dice sobre Edipo y lo que encontramos relatado en la Tebaida. Según Esquilo, Edipo se quitó los ojos tras revelarse que Yocasta era su madre. Esto, también, forma parte de la versión mítica que para nosotros es tradicional. No se nos dice nada respecto de lo que aconteció con Yocasta. Tampoco hay señales de ella en Los siete contra Tebas, por lo cual debemos suponer, junto a Pisandro y Sófocles, que se haya suicidado luego de la revelación.

${ }^{40}$ A., Th., 750-756. Salvo donde se indique lo contrario, para Los siete contra Tebas seguimos la traducción de Perea 1982.

${ }^{41}$ A., Th., 779-783.

${ }^{42}$ A., Th., 785 . 
iii. Ahora bien, por otra parte, la ceguera de Edipo parece complicar la posibilidad de lo que se nos cuenta en el tercer fragmento. En efecto, en consonancia con lo que sabemos a partir de nuestra lectura de la Tebaida, Esquilo nos dice que hubo una comida en la que Edipo maldijo a sus hijos augurándoles fratricidio mutuo. Tratándose de una comida debemos suponer que el Coro se refiere a la segunda de las dos maldiciones que Edipo arrojara contra sus hijos, ya que allí acontece el episodio en que le entregan huesos en lugar de carne. Como sea, puede suponerse que tanto el episodio de la copa como el episodio del anca hayan tenido lugar en el mismo momento, y de ahí que ambas maldiciones se atribuyan a la misma escena. Por otro lado, teniendo en cuenta que la versión de Esquilo sostiene que Edipo se cegó inmediatamente después de conocer la verdad, podemos suponer que reconoció la copa de algún otro modo.

Quedémonos con el hecho de que Edipo permaneció en la ciudad luego de revelarse su condición. No hay un destierro en la versión que nos transmite Esquilo, lo cual coincide con lo que pudimos averiguar en la épica arcaica, tanto a partir de los fragmentos que conservamos del Ciclo tebano como a partir de lo que Homero cuenta en la Odisea.

Dicho esto, hay un verso más que quisiéramos traer a consideración para resumir qué es lo que Esquilo ha tenido en mente mientras compone Los siete contra Tebas. Se trata de una exclamación que sale de boca de Antígona, personaje que aparece junto a su hermana Ismene hacia el final de la pieza, para lamentar la trágica muerte de sus dos hermanos: ;Ay, ay! iDescanse este dolor junto a su padre !3 $^{43}$ Este verso legitima lo que Homero nos contaba en torno a Euríalo y su llegada al funeral de Edipo, por lo que podemos afirmar que, también según Esquilo, Edipo murió y fue enterrado en Tebas, lo que nos confirma que, durante el enfrentamiento de Eteocles y Polinices, Edipo ya estaba muerto y, además, vivió hasta el final de sus días en la ciudad; algo muy distinto de lo que sabemos a partir de la versión que Sófocles inmortalizara en su Edipo Rey.

\section{FENICIAS 4}

Antes de continuar, debemos recordar al lector aquella hipótesis que adelantamos más arriba, la que sostenía que el fratricidio griego - ahora más con-

\footnotetext{
${ }^{43}$ A., Th., 1004.

${ }^{44}$ Se trata del drama más extenso de Eurípides y de toda la tragedia conservada. Sólo lo aventaja en número de versos el Edipo en Colono de Sófocles. No obstante, existen controversias respecto de la autenticidad de varios pasajes. Cf., Haslam 1976, pp. 4-10.
} 
cretamente tebano - debía significar algo más que el cumplimiento de una maldición del padre. En efecto, hemos visto a partir del Ciclo tebano y, luego, abordando Los siete contra Tebas, que la maldición oficia como elemento clave a la hora de comprender el desenlace fratricida. De alguna manera, es el padre, Edipo, el que con sus augurios ha decretado lo que sucederá luego en la ciudad, que verá a sus dos gobernantes muertos. Tanto la Tebaida como la obra de Esquilo refuerzan esta idea. No obstante, veremos que la pieza euripídea presenta una serie de elementos originales que modifican completamente las versiones que hemos tratado hasta el momento. Creemos que es a partir de esas modificaciones, de esos giros argumentativos, que Eurípides manifiesta su pensamiento. Lo que haremos a continuación es, en efecto, tratar de interpretar lo que con esas innovaciones el poeta quiere comunicarnos.

\section{1. La visión}

Vamos a comenzar con un rasgo harto señalado 45 que en principio ha sido comprendido como una inclinación de estilo por parte de Eurípides. Se trata de la marcada proliferación de escenas en las que la visión se vuelve un elemento primario en la percepción de los personajes. A diferencia de Los siete contra Tebas, donde Esquilo refuerza el sentido de la audición, ${ }^{46}$ mediante el cual los personajes tienen conciencia de lo que sucede más allá de las murallas, Eurípides recupera la teichoscopia homérica para dar a conocer al espectador lo que acontece en el campo enemigo. La escena que por su parecido nos remite más marcadamente al emblemático canto $\Gamma$ de la Ilíada ${ }^{47}$ es la siguiente:

AntíGona: ¿Quién es ese del penacho blanco, que avanza al frente del ejército blandiendo con ligereza en su brazo un escudo todo de bronce?

Pedagogo: Un jefe de escuadrón, señora...

ANTíGona: ¿Quién, de dónde procede? Aclárame, anciano, cómo se llama. ${ }^{48}$

Y luego:

ANTíGona: ¿Dónde está el que nació de la misma madre que yo, en un aciago destino? Ah, queridísimo anciano, dime, ¿ ¿ónde está Polinices? ${ }^{49}$

\footnotetext{
${ }^{45}$ Foley 1985. En esta obra el autor hace referencia a algunos de los aspectos que señalaremos a continuación, aunque su acercamiento sostiene una perspectiva de índole estilística. Veremos que otro abordaje es posible.

${ }^{46}$ V.g.A., Th., 83, 95, 100, 102, 152, 160, 203, 245, 253. El más sugestivo de entre ellos es el

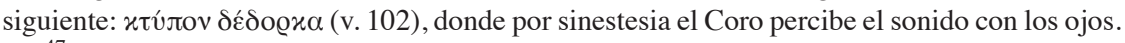

${ }^{47}$ Hom., Il., III, 161-240.

${ }^{48}$ E., Ph., 120-124. Salvo donde se indique lo contrario, para Fenicias seguimos la traducción de Calvo, García Gual y Cuenca 1982.

${ }^{49}$ E., $P h ., 156-158$.
} 
Somos testigos de una escena en la que Antígona pide al Pedagogo que le explique quiénes son aquellos que están en el campo enemigo. La muchacha sube hasta el piso superior del palacio para avistar lo que sucede fuera, mientras el anciano responde sus insistentes preguntas producto de su ignorancia respecto de la identidad de aquellos a quienes llega a ver. Antígona ve lo que está sucediendo y es el Pedagogo quien completa la información que ella no posee. Esta escena vendría a ser la homóloga de la escena de los escudos de Esquilo, sólo que aquí prima una narración de inspiración visual, mientras que en la otra es la audición la protagonista.

Con respecto al antecedente homérico, la versión de la teichoscopia euripídea presenta algunas diferencias, pero la coincidencia más sugestiva, y que nos hace pensar que se trata de un recurso poético deliberado, es aquella que constituye el último verso que hemos citado, en el que Antígona pregunta por Polinices, a quien no llega a distinguir. Si tomamos el texto homérico, veremos que algo similar importuna a Helena, quien no puede ver a sus hermanos..$^{50}$

Ahora bien, ¿qué otra explicación podemos dar a este recurso que no apele exclusivamente a un gesto de estilo por parte de Eurípides? Puede que en esta instancia no llegue a advertirse completamente, pues hay otros elementos que requieren ser aclarados, pero lo que queremos proponer es apreciar esta innovación contrastándola con la condición que signa la situación de Edipo: su ceguera. En efecto, a diferencia de lo que sucede en la versión de Esquilo, en Fenicias Edipo forma parte del elenco de personajes, pero su realidad es totalmente ajena a la del resto. Edipo se encuentra encerrado en el palacio, presa de su ceguera, maldiciendo a sus hijos. En el monólogo con que abre la pieza, Yocasta nos dice:

Y, a penas se sombreó de barba el mentón de nuestros hijos, ellos ocultaron bajo cerrojos a su padre, para que su infortunio quedara olvidado, lo que requiere muchos trucos. Aún vive en el interior del palacio. Desvariando a causa de la desdicha, invoca sobre sus hijos las más impías maldiciones: que con el afilado hierro desgarren esta casa. ${ }^{51}$

De acuerdo con la versión que nos presenta Eurípides a través del parlamento de Yocasta, Edipo permanece en el palacio tras la revelación de su verdad. Los versos citados se pronuncian luego de que Yocasta cuenta el episodio en que su esposo se quitó los ojos. Con lo cual, en consonancia

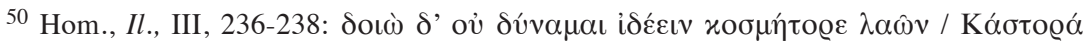

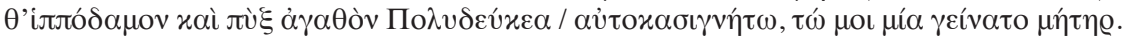
("Sólo a dos de quienes huestes dirigen no puedo ver / a Cástor domador de caballos y al guerrero experto Polideuces / mis dos hermanos, pues los engendró también mi madre").

${ }^{51}$ E., $P h ., 64-70$. 
con algunas de las versiones que hemos visto más arriba, Edipo permaneció en Tebas luego de las noticias trágicas; pero aquí se nos dice que lo hizo en condiciones de encierro, pues sus propios hijos, Eteocles y Polinices, son los que echaron el cerrojo. Se hace evidente que el recurso a través del cual Eurípides pondera la visión como el sentido por antonomasia mediante el cual los personajes perciben la escena, se opone a la situación de Edipo, quien no sólo es invidente, sino que además permanece en situación de encierro. Es como si dos piezas paralelas acontecieran a la vez. Por un lado, Yocasta, Antígona, Eteocles, Polinices y el resto de los personajes que dan vida a las escenas que suceden extra muros. Por otro lado, Edipo, quien aparece solo, recluido, vociferando maldiciones contra sus hijos. Respecto a esto último, Yocasta no nos informa la existencia de una comida hostil como lo hacían la Tebaida y Esquilo, por lo que debemos suponer que las imprecaciones de Edipo responden al hecho de que sus hijos lo hayan confinado al aislamiento.

\section{2. El encuentro}

Hablaremos ahora de un episodio que debemos también a la originalidad de Eurípides. Se trata del encuentro entre Polinices, Yocasta y Eteocles antes de la batalla que tendrá como desenlace la muerte de los dos hermanos y la de la propia madre. Esta reunión responde a la necesidad de Yocasta de convencer a sus hijos de desistir del enfrentamiento, solicitando a Polinices tener un encuentro con el objetivo de disuadirlo respecto de su decisión de reclamar su derecho al trono mediante la fuerza. Polinices acepta y, en son de paz, se aleja de su campamento y acude a la ciudad.

El encuentro entre la madre y el hijo está cargado de emoción; por fin, Yocasta, después de tanto tiempo, ve otra vez a Polinices. Seguidamente, Yocasta refiere su aspecto físico y las razones de su condición, contando, a su vez, el estado en que se encuentra Edipo:

[...] he cortado mi cabello gris, llorando he cedido en señal de luto mi cabellera despojándome de peplos blancos, hijo mío, y los he trocado por estos andrajos oscuros lúgubres. Y el anciano, desde que la pareja fraterna se desgajó del hogar, alberga sin cesar el arrepentimiento cubierto de lágrimas. Se arrojó tras una espada para un golpe suicida, y trató de ahorcarse de una viga, deplorando sus maldiciones sobre sus hijos. Entre incesantes aullidos de desesperación se esconde en las tinieblas. 52

Este fragmento contiene una serie de elementos en los que debemos detenernos. En primer lugar, Yocasta refiere que se ha afeitado la cabeza en

${ }^{52}$ E., $P h ., 321-335$. 
señal de duelo ${ }^{53}$ por el exilio de su hijo Polinices. Líneas antes se describe el vacío que su hijo dejó en la casa paterna tras verse forzado a la expatriación con la intención de evitar que se cumplan las maldiciones de Edipo ${ }^{54}$ Ante esto, Yocasta, presa del sufrimiento de una madre, decide vestir luto. Pero luego se nos habla de Edipo, quien, como sabíamos, se encuentra encerrado en el palacio. No obstante, el tormento que suponíamos lo aquejaba se nos revela todavía más hondo: Edipo ha intentado suicidarse en más de una ocasión. Según nos dice Yocasta, el sufrimiento que lo impulsó a acabar con su vida reside en un arrepentimiento que lo oprime desde que Polinices se vio obligado a dejar su patria. Eurípides nos presenta un Edipo arrepentido de las maldiciones que arrojara contra sus hijos, maldiciones que amenazan su estabilidad psíquica al punto de haber intentado acabar con sus días en dos ocasiones. Aparentemente, Edipo quisiera poder revertir aquel fratricidio anunciado por su propia boca o, en su lugar, quitarse la vida para librar la carga de su arrepentimiento. ${ }^{55}$ No obstante, ambas salidas le serán vedadas.

Vayamos ahora al diálogo entre Yocasta y Polinices. El pasaje que nos interesa es el siguiente:

YocaSTA: Bien, te preguntaré primero lo que deseo saber. ¿Qué es estar privado de la patria? ¿Tal vez un gran mal?

Polinices: El más grande. De hecho, es mayor de lo que pueda expresarse.

Yocasta: ¿Cuál es su rasgo esencial? ¿Qué es lo más duro de soportar para los desterrados?

Polinices: Un hecho es lo más duro: el desterrado no tiene libertad de palabra.

$[\ldots]$

YOCASTA: La patria, según se ve, es lo más querido a los mortales..$^{56}$

Yocasta se muestra interesada respecto a lo que constituye estar privado de la patria, pero lo curioso es que su pregunta no se dirige directamente a la expatriación que sufriera su hijo Polinices, sino que indaga en un sentido

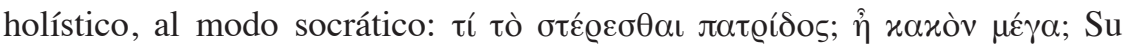
pregunta pretende conocer la condición del desterrado, procura saber qué significa ser despojado de la tierra propia, qué sentimientos despierta esa confinación en el exiliado y cuáles son las peores desgracias que acarrea.

${ }^{53}$ Afeitarse la cabeza en señal de duelo o renuncia era algo frecuente en las civilizaciones antiguas. Explica en parte la práctica de la tonsura que se diera a principios de la Edad Media, cuyo origen el cardenal John Henry Newman (1909, p. 374) identifica en las culturas paganas.

${ }^{54}$ En efecto, el exilio de Polinices constituía una medida preventiva que tenía como fin evadir cualquier tipo de enfrentamiento que pudiera acontecer entre los hermanos en caso de que ambos continuaran conviviendo en la misma casa.

${ }^{55}$ Este rasgo que Eurípides imprime en la figura de Edipo logra humanizarlo. Edipo reconoce su hýbris y, aunque fisiológicamente ciego, intenta combatir su ceguera (ate) psíquica.

${ }^{56}$ Vv. 386-406. 
Polinices aduce que se trata de un mal más grande de lo que podría expresarse ( $\delta$ ' غ̇øtì $\mu \varepsilon \hat{\zeta} \zeta o v$ ì $\lambda$ ó $(\omega \iota)$, pues, según afirma: el desterrado no tiene

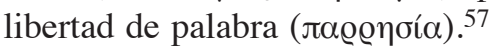

Hay dos elementos que quisiéramos señalar en relación a estas preguntas que Yocasta dirige a su hijo. En primer lugar, nos parece que Eurípides desea transmitir la idea del destierro como el peor castigo que puede sufrir un mortal. Esto nos queda claro al advertir las respuestas que Polinices da a su madre. Ahora bien, por lo que sabemos de la versión que el poeta manipula, el único que hasta el momento ha padecido el alejamiento de su tierra es Polinices. Edipo continúa en el palacio, como dijimos. Pero a pesar de ello, antes de arribar al desenlace de la pieza, Eurípides quiere manifestarnos por medio del hermano de Eteocles el dolor inconmensurable que significa estar alejado de la casa patria. Un episodio semejante lo encontramos en el Edipo en Colono de Sófocles, donde Polinices va al encuentro de su padre - quien permanece en el exilio junto con Antígona e Ismene - para rogarle que revierta las maldiciones que tiempo atrás arrojara contra él y su hermano:

Yo te pido por nuestras fuentes y por los dioses protectores de nuestro linaje que te dejes persuadir y cedas, ya que mendigos y extranjeros somos los dos y vivimos adulando a los demás tanto tú como yo, ya que el mismo destino hemos obtenido. 58

En la versión de Sófocles el muchacho sale de la ciudad para encontrarse con su padre en Colono, rogando su apoyo y cooperación en la batalla, para lo cual requiere se retracte de las maldiciones que antaño arrojara sobre él y Eteocles. Polinices intenta persuadir a su padre aduciendo la condición de exiliados que ambos sufren, ${ }^{59}$ por la cual, según nos dice, ambos viven

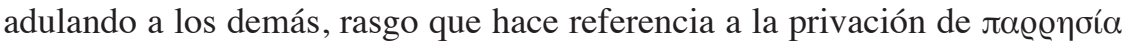
que Polinices indica en su respuesta a Yocasta en Fenicias.

Lo que afirmamos, entonces, es que Eurípides no arbitrariamente hace que la madre interrogue de este modo a su hijo; es evidente que el poeta manifiesta su visión del exilio. ${ }^{60}$ Pero lo que no nos queda claro todavía es

\footnotetext{
${ }^{57}$ Mucho se ha escrito sobre este concepto griego. Quizá la interpretación que más asidero ha logrado en los últimos años es la de Michel Foucault. Véanse las conferencias dictada por el filósofo en las Universidades de Grenoble y Berkeley en los años 1982 y 1983 respectivamente, recogidas en su versión española por la editorial Siglo XXI (2017).

${ }^{58}$ S., $O C ., 1333-1337$.

${ }^{59}$ Recurso frecuente en la tragedia. Eurípides da otro ejemplo de ello en Troyanas, donde el Coro de cautivas y Hécuba participan de la misma desdicha: ser obligadas al exilio bajo el dominio de un soldado griego (cf. E., Tr., 235-290).

${ }^{60}$ No debe perderse de vista que la vida de Eurípides, como la de muchos de sus contemporáneos, se encontró signada por el exilio. Siendo todavía un niño, a causa de la segunda Guerra Médica, debió exiliarse con su familia desde Flía o Salamina (existen dudas sobre su lugar de nacimiento) hacia Atenas. Luego, en el 408 (uno o dos años después de componer Fenicias y
} 
por qué. Es decir, qué implicaciones tiene esta noción - la del exilio como el castigo superior - en la pieza que tratamos.

\section{3. Edipo}

El final de este estudio lo encabeza el nombre del padre y no el de los hermanos, pues creemos que Fenicias se ocupa de él. Es en Edipo que todos los elementos que hemos estudiado hasta aquí se conjugan en significado. Restará, ahora, mostrar de qué manera.

García Gual y Bernabé Pajares sostienen ${ }^{61}$ la opinión de Pearson: "there is no central character whose fortunes overshadow those of the rest". ${ }^{62}$ Para estos autores, en efecto, la obra no posee un protagonista, pues consideran que no existe un personaje que concentre los sufrimientos y las desdichas que acontecen a lo largo y a lo ancho de sus eventos. Nosotros, en cambio, sostenemos que sí lo hay, y este no es otro que Edipo. Para demostrarlo, veamos primero lo que nos deja Eurípides como desenlace de la obra. Se trata de una escena que se inaugura con el lamento de Antígona ante la muerte de su madre y de sus hermanos. La joven exhorta a Edipo a que salga del palacio para ser testigo de lo que está aconteciendo. Seguidamente, por primera vez en toda la pieza, Edipo sale a escena y habla:

¿Por qué, hija, me has sacado a la luz, con los bastones que ayudan a mi ciego paso, desde los oscuros aposentos donde yacía echado...? $?^{63}$

Luego, Antígona cuenta a su padre lo que ha sucedido y Edipo exclama:

$\lceil$ Ay! ¡Ay! [...] Mis hijos...La muerte de mis hijos era una evidente fatalidad. Pero mi desdichada esposa ¿en qué triste trance, hija, pereció ${ }^{64}$

La joven vuelve a responder las demandas de su padre $y$, tras finalizar su parlamento, entra en escena Creonte, dirigiéndose a Edipo para anunciarle la decisión que ha tomado sobre él: confinarlo al destierro.

Para comprender qué significa todo esto debemos recordar aquel diálogo que señalamos en que Yocasta y Polinices se reencuentran en el interior de

dos antes de morir) se vio obligado a radicarse en Macedonia bajo la protección de Arquelao I, presionado por la convulsiva Guerra del Peloponeso.

61 "Por otra parte, no existe un protagonista trágico cuyos sufrimientos y catástrofe final concentren los sucesos": García Gual 1982, p. 82. Enrico Medda (2005) sostiene que es el Coro el que protagoniza Fenicias, conclusión a la que es sencillo arribar si uno da mayor importancia al título, aunque la argumentación del autor - a cuyas conclusiones, no obstante, no adherimos totalmente - es justa.

62 Pearson 1909, p. XXX.

${ }^{63}$ E., $P h ., 1540$.

${ }^{64}$ E., $P h ., 1560-1565$. 
la ciudad. Vimos a la madre inquiriendo a su hijo sobre el significado del exilio, arribando a la conclusión de que el destierro es lo más grave que puede sucederle a un mortal. Si nos detenemos en el final de la pieza, donde Edipo es forzado al ostracismo, podemos comprender de otro modo lo que hasta allí parecía ser sólo una conversación: el fratricidio tebano es, en la versión que nos ofrece Eurípides, mucho más que la ejecución de una maldición del padre; se trata, en efecto, del castigo al padre. Por ello decimos que la pieza tiene como protagonista a Edipo, ya que la serie de episodios que acontecen, si bien tienen como núcleo dramático el enfrentamiento entre los hermanos, no terminan en el fratricidio, sino que acaban en el exilio.

En su argumento de Fenicias, Aristófanes de Bizancio afirma que el final de la pieza - en que se dan la aparición y el destierro de Edipo- está añadido como un remedio superfluo. Nosotros, no obstante, interpretamos que Eurípides encuentra en el tradicional exilio edípico el hecho que resemantiza el fratricidio. En efecto, la expatriación de Edipo - en el Edipo Rey de Sófocles - sobreviene luego de acaecido el suicidio de Yocasta y antes de la contienda entre Eteocles y Polinices. En Fenicias, en cambio, la partida de Edipo solo es posible una vez que los hermanos se hayan ultimado y la madre, entre llantos, haya acabado con su vida.

Lo que afirmamos, entonces, es que en la visión de Eurípides el fratricidio debía ser conjurado contra Edipo, quien protagoniza la pieza en off. Su aparición hacia el final es indudablemente deliberada. Si prestamos atención a la caracterización que hace de él mismo, Edipo refiere a "los bastones que ayudan a mi ciego paso". ${ }^{65}$ Debemos figurarnos lo que esa imagen pudo haber forjado en la mente de los espectadores: Edipo, emergiendo de su aislamiento, viejo, malogrado, ciego y con bastón en mano. Se trata, nada menos, que de la resolución del acertijo de la Esfinge. Si leemos atentamente el argumento que nos ha llegado junto al texto de la tragedia, en una de sus partes vemos relatado el enigma al que debió enfrentarse Edipo cuando llegó a Tebas, junto con su resolución. Algunos autores ${ }^{66}$ han visto este agregado como un elemento sin sentido, pero creemos que se trata de un dispositivo que pretende señalar a Edipo como la respuesta a su propio misterio. Es el bastón que el propio Edipo menciona el que nos revela su condición, y es Eurípides quien insiste en el objeto cuando, en el momento que Edipo sale al exilio, acompañado de Antígona, dice:

¿Por dónde pongo mi viejo pie? Dame el bastón, hija. ${ }^{67}$

\footnotetext{
${ }^{65}$ E., $P h ., 1541$.

${ }^{66}$ Cf. Kitto 1939, pp. 354-366.

${ }^{67}$ E., $P h ., 1719$. Típico recurso clásico de indicio de vejez. Cf. E., Andr., 550-555.
} 
Por supuesto no podemos basar nuestras conjeturas a partir de la mera mención de un bastón; se trata, en realidad, de un elemento que suma al conjunto que estamos tratando de determinar. Edipo es, según nuestra lectura, el personaje en el que se realizan los actos que se han cometido a lo largo de toda la pieza. Es él, el padre, en quien las maldiciones que arrojara antaño hallan término. La innovación de Eurípides en hacer permanecer a Edipo en el palacio no es arbitraria. De hecho, la respuesta a esa aparición - que era nuestra incógnita - es el merecido destierro.

Antígona pregunta a su padre: “¿dónde está el Edipo de los famosos enigmas?", ${ }^{6}$ y él no tiene más que responder:

Ya no existo. Un solo día me encumbró y uno me hundió. ${ }^{69}$

Edipo, quien antaño resolvió el enigma, es ahora presa de sus evocaciones. Eurípides es el poeta que, a través del drama, vuelve al fratricidio de Eteocles y Polinices un castigo dirigido al padre.

\section{CONCLusión}

Hemos observado que el fratricidio constituye el núcleo dramático de nuestra pieza y que, a su vez, se alza como un tema recurrente en la cultura de Occidente, por lo que debimos llevar adelante un relevamiento que contempló diversas áreas del pensamiento que eventualmente han abordado la experiencia del fratricidio a partir de fuentes en que ella es decisiva. Así, nos dirigimos hacia el psicoanálisis, la antropología, la literatura y la filosofía, con el objetivo de probar la riqueza temática de nuestro tópico y ampliar la mirada que de él teníamos. Una vez realizado esto, dirigimos nuestra indagación hacia la determinación de nuestro tema. En efecto, al no poder abordar aquí el fratricidio en la totalidad de sus expresiones, redujimos nuestro tratamiento a lo expresado en la tragedia griega clásica tomando como punto de partida el material aportado por la épica arcaica. Una vez precisada nuestra fuente, el interrogante que nos acompañó durante todo el desarrollo de la investigación fue el siguiente: ¿qué significa el fratricidio tebano en la pieza euripídea? ¿Qué nos quiere comunicar el poeta a través de él? Nuestra hipótesis sostenía la idea de que este fratricidio debía ser más que el mero cumplimiento de una maldición de Edipo, ya que intuíamos que las modificaciones e innovaciones que Eurípides forjó sobre el mito que sustentaba la versión de su composición querían decirnos algo más. Sin embargo, no podíamos lanzarnos directamente a estudiar nuestro texto sin antes

\footnotetext{
${ }^{68}$ E., $P h ., 1688$.

${ }^{69}$ E., $P h ., 1689$.
} 
dar pruebas de los abordajes que sobre este tema se habían realizado antes de que Eurípides compusiera su obra, por lo que examinamos las fuentes sobre cuyo contraste se iluminaría nuestra pieza: el Ciclo tebano y Los siete contra Tebas de Esquilo.

En cuanto a Fenicias, nuestra exploración arribó a la siguiente conclusión general: a partir de la versión mítica que Eurípides adopta, el fratricidio no es tan sólo la ejecución de la maldición del padre, sino que se alza como el castigo dirigido a él mediante su exilio. En efecto, sólo a partir del exterminio fratricida y los sufrimientos que este acarrearía para Yocasta, llevándola a un trágico suicidio, es lícito que Edipo saliera de su confinamiento para que, inmediatamente, le sea decretado el ostracismo, experiencia que Eurípides se había ocupado en caracterizar a partir del diálogo entre Polinices y su madre cuando aquel ingresa a la ciudad en señal de tregua.

Al mismo tiempo, a partir de algunas referencias que van del argumento al final de la pieza, pudimos advertir cómo hay una insinuación por parte de Eurípides de la resolución del enigma de la Esfinge en la propia figura de Edipo, quien ciego y viejo, con la ayuda de un bastón, abandona la ciudad.

Este trabajo ha pretendido ser un aporte cuyo horizonte de estudio específico ha sido la tragedia griega en vistas de un tópico: el fratricidio, abordado en una pieza en particular. Este acotamiento responde tanto a las exigencias de este estudio en general como a las exigencias de nuestro método en particular, pues un abordaje de la dimensión filosófica de la tragedia exige un estudio de los textos, en cuyo examen se busque conocer aquello que el poeta se esforzó en mostrarnos. En este sentido, nuestra perspectiva se diferencia de la que Platón y Aristóteles han llevado a cabo sobre la tragedia. En efecto, si bien ambos han explorado su contenido, lo han hecho no en el sentido que aquí priorizamos, sino en amparo de su propio pensamiento. Por un lado, en Platón no hay un abordaje estricto de alguna pieza trágica en particular. El filósofo no se ocupó de comprender lo que los poetas querían comunicar, sino que le preocupaba que se comunique lo que él creía necesario para la $\pi$ ó $\lambda\lrcorner$, de acuerdo con su concepción de la correcta educación

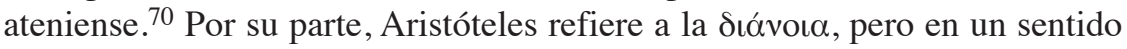
meramente estructural, para referirse con ello al diálogo pronunciado por los personajes. ${ }^{71} \mathrm{Si}$ bien la obra de Aristóteles ha sido fundamental para el desarrollo de todos los estudios posteriores en relación a la tragedia, su abordaje no explora el contenido como aquí lo hemos entendido.

En el mismo espíritu es que no queremos dejar de referirnos a una de las obras modernas más influyentes sobre la tragedia, nada menos que Die

\footnotetext{
70 Véase Rep., 376-403.

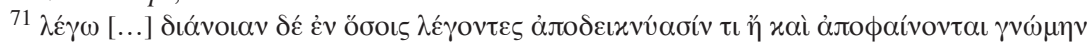
(Poet., 1450a 6).
} 
Geburt der Tragödie, opera prima de Friedrich Nietzsche. Este texto, que presenta una serie de resultados excepcionales y que en su tiempo motivó una de las polémicas eruditas más interesantes de la escena decimonónica, ${ }^{72}$ presenta características metodológicas que no se distancian mucho del estagirita. En efecto, los pocos comentarios que Nietzsche expresa sobre algunas tragedias en particular son exiguos y algo débiles. El filósofo - o tal vez debamos llamarlo aquí filólogo- lleva adelante un trabajo notable, cuyas conclusiones aún hoy son objeto de estudio; la ruptura de su enfoque con el racionalismo durante tantos siglos atribuido al espíritu griego ha sido uno de sus más acertados golpes. Sin embargo, a pesar de sus buenos resultados, debe reconocerse que su abordaje de la tragedia en particular es casi nulo. Tal vez éste no haya sido su objetivo, lo cual es suficiente para excusarlo.

Mucho ha quedado fuera, pero a la vez estamos convencidos de que estos vacíos podrán ser enmendados en futuros trabajos, siempre bajo la convicción de que "to come of age, the philosophy of tragedy must first of all develop some sense of reality, some feeling of responsibility to evidence, some interests in specific poems". ${ }^{73}$

\section{BIBLIOGRAFÍA}

Para el estudio de las fuentes originales en griego de Esquilo, Sófocles y Eurípides hemos consultado las versiones del Thesaurus Linguae Graecae, Perseus Project (versión 3.1 .6) 1999-2007 de P. J. Heslin, junto con las versiones aparecidas en la herramienta virtual Loebolus (https://ryanfb.github. io/loebolus/). A su vez, para el tratamiento de los fragmentos y testimonios de comentaristas y escoliastas contenidos en el Ciclo tebano, nos hemos servido de Bernabé Pajares, A., Fragmentos de épica griega arcaica, Gredos, Madrid, 1999.

\section{Fuentes antiguas}

Aristóteles, Poética, ed. trilingüe (griego-latín-español) V. García Yebra, Madrid, Gredos, 1974.

Esquilo, Los siete contra Tebas, en Tragedias, trad. B. Perea, Madrid, Gredos, 1982.

EuRíPIDEs, Fenicias, Andrómaca y Troyanas, en Tragedias (vol. III), trad. J. L. Calvo, C. García Gual y L. A. de Cuenca, Madrid, Gredos, 1982.

EuRíPIdes, Phoenissae, trad. e intr. A. C. Pearson, Cambridge, Cambridge University Press, 1909.

\footnotetext{
72 Véase "La polémica sobre El nacimiento de la tragedia" en Nietzsche 2011, pp. 861-951.

${ }^{73}$ Kaufmann 1968, p. 101.
} 
Homero, Ilíada, ed. bilingüe (griego-español) F. J. Pérez, Madrid, Abada, 2016.

Homero, Odyssee, ed. bilingüe (griego-alemán) A. Weiher, München, Tusculum, 1967.

Horacio, Épodos, ed. bilingüe (latín-español) A. Beber, Buenos Aires, Losada, 2010.

Platón, República, trad. C. Eggers Lan, Madrid, Gredos, 1982.

Sófocles, Edipo Rey y Edipo en Colono, en Tragedias, trad. A. Alamillo, Madrid, Gredos, 1982.

\section{Fuentes modernas}

Albizu, E., Teoría del contratiempo implosivo, Buenos Aires, Ediciones del Signo, 2006.

Ambuhl, A., Krieg und Burgerkrieg bei Lucan und in der griechischen Literatur. Studien zur Rezeption der attischen Tragodie und der hellenistischen Dichtung im Bellum civile, Berlin, De Gruyter, 2015.

BauzÁ, H. F., El mito del héroe. Morfología y semántica de la figura heroica, Buenos Aires, Fondo de Cultura Económica, 2007.

Bloom, H., El canon occidental, trad. D. Alou, Barcelona, Anagrama, 1995.

Carruba, R. W., "The Curse on the Romans", Transactions and Proceedings of the American Philological Association, 97, 2014, pp. 29-34, http://dx.doi. org/10.2307/2935999.

CRIADO, C., "The Theban Fratricidal Wars. The Mythic-Historical Aproach of Ovid, Seneca and Lucan", en Mercedes Díaz de Cerio Díez, Concepción Cabrillana and Cecilia Criado (eds.), Ancient Epic: Literary and Linguistic Essays, Cambridge, Cambridge Scholars Publishing, 2015.

Foley, H. P., Ritual Irony. Poetry and Sacrifice in Euripides, Ithaca and London, Cornell University Press, 1985.

Foucault, M., El gobierno de sí y de los otros, trad. H. Pons, Madrid, Akal, 2011.

Foucault, M., Discurso y verdad: conferencias sobre el coraje de decirlo todo. Grenoble 1982 / Berkeley 1983, ed. E. Castro, Buenos Aires, Siglo XXI, 2017.

Frazer, J. G., El folklore en el Antiguo Testamento, trad. G. Novás, México, Fondo de Cultura Económica, 1981.

Freud, S., Obras completas, trad. L. López Ballesteros y de Torres, Madrid, Biblioteca Nueva, 2017.

Goux, J. J., Edipe philosophe, París, Aubier, 1990.

Goux, J. J., Edipo filósofo, trad. L. Pinkler, Buenos Aires, Biblos, 1999.

Grimal, P., Historia de Roma, trad. L. Vermal, Barcelona, Planeta, 2005.

Haslam, M. H., "Interpolations in the Phoenissae: Papyrus evidence", The Classical Quarterly. New Series, 1, 1976, pp. 4-10, http://dx.doi.org/10.1017/ S0009838800033759.

Hozven, R., "El modelo genético de Claude Lévi-Strauss", Boletín de Filología de la Universidad de Chile, 30, 1979, pp. 51-89.

JASPERS, K., Über das Tragische, München, R. Piper y Co. Verlag, 1947.

Kaufmann, W., Tragedy and Philosophy, New York, Doubleday \& Company, 1968.

KITTO, H. D. F., Greek Tragedy, Londres, Methuen \& Co., 1939. 
LÉVY-Bruhl, L., Le Surnaturel et la Nature dans la mentalité primitive, París, Les Presses Universitaires de France, 1931.

Lipscomb, W. L., The Armenian Apocryphal Adam Literature, Atlanta, University of Pennsylvania, Peeters Publishers, 1990.

Marcuse, H., Eros y civilización, trad. J. G. Ponce, Madrid, Ariel, 1983.

Marx, K., The Capital, Salt Lake City, University of Utah (bilingual digital ed.), 2002.

Medda, E., "Il coro straniato: considerazioni sulla voce corale nelle Fenicie di Euripide", Prometheus, 31, 2005, pp. 119-131.

Newman, J. H., An Essay on the Development of Christian Doctrine, 1909, www. newmanreader.org/works/development/index.html\#titlepage (01/09/2020).

Nietzsche, F., Obras completas I. Escritos de juventud, ed. D. Sánchez Meca, Madrid, Tecnos, 2011.

Rank, O., Der Mythus von der Geburt des Helden: Versuch einer psychologischen Mythendeutung, Leipzig, Deuticke, 1909.

Rank, O., The Myth of the Birth of the Hero. A Psychological Interpretation of Mythology, trad. F. Robbins, New York, The Journal of Nervous and Mental Disease Publishing Company, 1914, http://dx.doi.org/10.1037/11396-000.

ZweIG, S., La lucha contra el demonio: Hölderlin - Kleist - Nietzsche, trad. J. Verdaguer, Barcelona, El Acantilado, 1999.

Bruno D. Alfonzo es licenciado en Filosofía por la Universidad Nacional de San Martín (Buenos Aires, Argentina). Coordinador del grupo de traducción de textos filosóficos y literarios en lengua inglesa e integrante de los grupos de traducción de textos filosóficos en griego ático y latín medieval dependientes de la misma Universidad. Ayudante en la cátedra de Historia de la Cultura Clásica en la Escuela de Humanidades, asignatura a cargo del Dr. Hugo F. Bauzá. Su línea de investigación se circunscribe en el mundo clásico, con especial énfasis en la tragedia griega. Sus publicaciones más recientes son: "Las humanidades. Notas para una historia institucional (Ubierna, P., ed. unipe, 2016)", en Patristica et Mediaevalia, 40(2), 2019, pp. 93-95 y "Personas, cosas, cuerpos (Esposito, R., ed. Trotta, 2016)", en Tópicos, 56 , pp. 458-464. 